\title{
"My heart was so painful": A Narrative Inquiry into the Impact of Immigration Status, Violence, Disability and Poverty on Identity Construction
}

\author{
Joanne Neille* and Claire Penn \\ School of Human and Community Development, University of the Witwatersrand, Johannesburg, South Africa
}

\begin{abstract}
Violence among immigrant women is a growing concern internationally. A number of studies have used surveys, structured questionnaires and secondary analysis in order to investigate various aspects of vulnerability that place immigrant women at risk for being exposed to violence. However, little attention has been paid to the ways in which contextual influences intersect and overlap, deepening the immigrants' sense of vulnerability. In this paper we present a single case study, conducted in rural South Africa, of a female immigrant with a disability, living in a context dominated by violence and poverty. A narrative inquiry method was employed in order to provide insight into the impact that context, immigration status and disability have on identity construction. Findings were analysed using both thematic and narrative analysis, according to the positioning of the narrator, characters and events within the story; the temporal and spatial domains within which events were constructed; and the development of a narrative plot. Findings revealed that the context of violence and poverty was central the way in which life experiences were interpreted. The complex combination of horror and trauma which the participant experienced served to threaten her sense of self, resulting in a narrative devoid of sequence and consequence, and ultimately an incoherent sense of self. Narrative inquiry was shown to be a potentially valuable tool for exploring intersecting aspects of lived experience and for providing insight into the ways in which these experiences impact on identity construction. Importantly, the findings highlight the value of listening to unconventional narratives in order to understand the reality of lived experience among immigrant women.
\end{abstract}

Keywords: Immigrant women; Violence, Disability; Poverty; Narrative inquiry; Identity; Intersectionality

\section{Introduction}

Violence among immigrant women is a growing concern internationally [1-4]. While the literature suggests that the life experiences of female immigrants are dominated by violence and sexual exploitation, gender inequality, victimisation, and mental health problems [1-3,5], little attention has been paid to the ways in which contextual influences intersect and overlap, deepening immigrants' sense of vulnerability. It is acknowledged that being a female and being an immigrant significantly increases an individual's sense of vulnerability $[2,3,5]$, however, the experience of being disabled further weakens their defences, placing them at risk for social isolation, marginalisation, exploitation and exposure to violence [6,7]. Although a paucity of literature exists on the prevalence of disability amongst immigrants, it can be inferred to be high, based on the fact that disability affects vulnerable populations disproportionately [8].

The onset of a disability and the experience of immigration are both considered to be major life-changing events, and it is therefore inevitable that these individuals will be faced with challenges to their identities. In many cases this is further impacted on by the experience of violence. While numerous studies have researched the impact of immigration, violence or disability as discrete components of identity construction, to our knowledge no studies have focussed on the intersectionality of all of these factors, while taking into account the impact that context has on identity construction. By employing narrative inquiry as a culturally and contextually appropriate tool, this paper will make use of a single case study to explore the intersectionality between disability, violence and context on identity construction as experienced by a female immigrant in rural South Africa.

Research reflects that in developed countries the lifetime prevalence of violence among ever-partnered women ranges from 15\%-37\% [9], while in Sub-Saharan Africa up to $71 \%$ of women report the experience of physical, sexual or psychological violence in close relationships [9]. The risk of violence is known to increase among younger women, those who are uneducated and illiterate [10], and those who are made vulnerable by disability, poverty, and food insecurity $[6,11,12]$. In African societies vulnerability to violence is further impacted on by patrilineal systems of decent and inheritance which allow men dominance over women [13]. While little data exists specifically on the prevalence of violence directed towards migrant women, it can be inferred to be high given their vulnerability. This is supported by research which suggests that the everyday life experiences of women immigrants are dominated by a variety of physical and sexual violations [1-3,5]. However, consideration must be paid to the fact that there is very little data on exposure to less visible forms of violence, including structural violence, psychological violence and violence by means of deprivation. Anecdotal reports, however, suggest that these types of violence are rife amongst immigrant women and serve to further marginalise them, making them vulnerable to physical and sexual abuse [14].

South Africa provides a unique setting in which to explore the

*Corresponding author: Joanne Neille, School of Human and Community Development, University of the Witwatersrand, Johannesburg, South Africa, Tel: +2711 717 4574; Fax: +2786 553 6060; E-mail: joanne.neille@wits.ac.za

Received February 28, 2014; Accepted July 04, 2014; Published July 11, 2014

Citation: Neille J, Penn C (2014) "My heart was so painful": A Narrative Inquiry into the Impact of Immigration Status, Violence, Disability and Poverty on Identity Construction. Arts Social Sci J S1: 007. doi: 10.4172/2151-6200.S1-007

Copyright: ( 2014 Neille J, et al. This is an open-access article distributed under the terms of the Creative Commons Attribution License, which permits unrestricted use, distribution, and reproduction in any medium, provided the original author and source are credited. 
ways in which context impacts on the experience of immigration and disability. The country's history of cultural, political and racial disputes has resulted in a culture of violence [15], with South Africa currently considered to be amongst the most violent countries in the world [15]. Despite the fact that South Africa is considered to be one of the wealthiest countries in the African continent [16] many people live below the breadline, with rural areas plagued by low levels of literacy, high rates of unemployment, high prevalence of disability and largely uncontrolled spread of disease [17]. This is further impacted on by the influx of up to eight million legal and illegal immigrants having entered the country [18]. While the South African constitution protects the rights of both resident and non-resident citizens to dignity, equality, justice, basic education and healthcare, and labour rights [19], the additional demands which immigrants place onto an already strained government sector has led to numerous outbreaks of xenophobic violence [20].

The literature reflects that both immigrants and people with disabilities are at significant risk for exposure to violence since they are likely to experience exclusion, exhibit dependence on others, have reduced physical and emotional defences, and experience communication barriers, stigma, and discrimination $[3,5,6,11,12]$. Vulnerability is further increased by unequal power dynamics, poor social support structures, lack of ability or opportunity to report on experiences of violence, financial or emotional dependence on the perpetrator, and repeated exposure to violence over the course of a lifetime $[11,12,21]$. This makes both immigrants and people with disabilities susceptible to multiple forms of violence, including structural violence; physical, sexual and emotional exploitation; and violence by means of deprivation [22]. All of these forms of violence have the potential to impact on the development of a resilient identity.

The concept of identity is considered to be a fluid notion which changes over time and according to context [23,24]. It is commonly accepted that many immigrants face challenges to their identity, with perceived cultural, ethnic and religious discrimination [2-5]. Cameron [25] suggests that the key components to take into account in the study of migrant identity include self-identification, sense of belonging, attitudes towards the in-group, centrality of group membership, and group involvement [25]. In addition, social identity categories, including race, class and gender have been proposed as important constituents of identity [5]. These aspects of identity construction have traditionally been considered as discrete units and have conventionally been studied from either a behavioural or psychological perspective [3]. In recent years, increasing attention has been paid to the intersections of various biological, cultural and social categories, including gender, race, class, and ability on identity construction [5] with intersectionality theory becoming one of the most widely accepted paradigms for understanding identity construction [26]. This implies that the various axes of identity construction interact on multiple and often simultaneous levels [5] all of which serve to constrain or enhance an individual's interpretation of their experiences [24]. Thus resilient identity construction depends on the individual's ability to make sense out of their experiences relative to their personal history, and social and cultural affiliations.

Despite the growing attention paid to violence against immigrant women $[1,2,4,5,9,10]$, the literature reflects that few women are confident to speak out about the way in which they have made sense of these experiences [2,4], thus impacting on our understanding of identity construction among this population. While this may partly be attributed to their sense of vulnerability and fear of speaking out
[2], difficulty in accessing support services [27-29], fear of xenophobia [3], and structural and linguistic barriers to accessing support [17], consideration must be given to the theoretical approaches that have traditionally been adopted when studying these experiences. A review of the literature reflects that the most common methods used to research into the experiences of immigrant women include surveys [2,4,29], focus groups $[5,28]$, structured questionnaires $[3,28]$ and secondary analysis of data collected for large-scale projects $[1,30]$. While it is acknowledged that these methods have the potential to illuminate some of the challenges facing immigrant women, the nature of the guiding questions inherent in these methods implies that the researcher controls the type of information given by containing the interview content. This suggests a focussed interest in a particular vulnerability without taking into consideration the ways in which a multitude of complexities intersect and overlap. This aligns with the notion that as researchers we are conditioned to hear stories with happy endings [31], and therefore use methods in which we have control over the content that the participant shares. Furthermore, data are frequently collected in languages which are not the participants' home languages and thus, the data collection methods or processes used may be considered to be culturally inappropriate or unsafe [32]. Conversely, the process of telling stories about lived experience may be considered a culturally safe tool [32] which is not reliant on literacy or level of education [33].

Narrative inquiry provides a unique opportunity to explore the various intersections of identity construction. The narrative construction of identity suggests that identity is made up of a variety of memories and emotionally significant experiences which shape and influence the way in which the individual reflects on and integrates them into their life story $[21,22,23]$. Significantly, some memories are consistent with the individual's sense of identity and are thus easily incorporated into the life story, while others challenge the individual's sense of self, rendering both experiences and life stories chaotic and unpredictable [34]. Regardless of whether memories conform to or disrupt the individual's sense of self, it is through the process of telling stories [31,34-39] that events and memories are isolated, reflected upon and incorporated into a sense of self [34].

Narrative inquiry places the participant in control of the interview setting and has the ability to reveal the multitude of complexities which impact on the ways in which sense is made of lived experience. Through telling stories, spatial and temporal boundaries are formed [37], events of the past are reconstructed [38], and characters are created and positioned relative to the narrator [40]. The relationship between these features gives rise to the development of narrative sequence and consequence, which leads to the development of a narrative plot $[41,42]$. By telling stories, individuals are able to make sense of experiences and events; integrate disparate roles, values and skills, and to organize the past, present and future into a meaningful pattern $[37,38]$. In this way the individual attempts to develop a sense of selfcontinuity and coherence through life's changes [34]. It is, however, important to consider that unstable living conditions, violence and disability have the potential to render life experiences as inconsistent and unreliable [34], generating a sense of narrative loss [31,42]. This may manifest in a sense of physical, emotional or psychological distress [31]. This sense of biographic disruption may create fractures within life stories, forcing the individual to restructure not only their physical life, but their narrative structures too [31].

Based on the above, this paper aims to make use of a single case study to demonstrate the value of narrative inquiry for providing 
insight into the impact that context, immigration status, violence and disability have on identity construction.

\section{Materials and Methods}

Permission to conduct this study was granted through the University of the Witwatersrand Non-Medical Ethics Committee [protocol number H090612].

The case study presented in the paper formed part of a larger study which investigated the experiences of adults living with disabilities in a rural area of South Africa [43]. Although aspects relating to violence against immigrant women were not specifically targeted in the main project, this emerged as a prominent theme.

Data were collected in a rural village in the Nkomazi East Municipality of the Mpumalanga Province of South Africa (Figure 1). This area is typically rural in nature, and is ravaged by the effects of poverty; burden of disease; limited access to healthcare, education and information; and high prevalence of disability.

The participant was a 53 year old woman who was born in South Africa but immigrated to Mozambique when she married a Mozambiquan National. The participant sustained a physical disability after being repeatedly stabbed in the back during the Mozambiquan war [1977-1992], resulting in paraplegia. Subsequent to sustaining the injury, the participants' parents brought her back to South Africa for medical treatment. However, her South African documentation was destroyed during the war, and thus, upon returning to South Africa she was regarded as an illegal Mozambiquan immigrant.

A qualitative design was adopted, underpinned by the principles of narrative inquiry, participant observation and researcher reflections. Narratives were collected in Siswati [one of South Africa's eleven official languages] and recorded on a digital audio-recorder by the first author and a SiSwati-speaking research mediator, who was a local resident of the community and who had a physical disability. The participant was visited in her home on three occasions over periods of two-three hours, as well as during daily activities in the community and at the disability centre that she attends. She was simply asked to "Tell her story", and

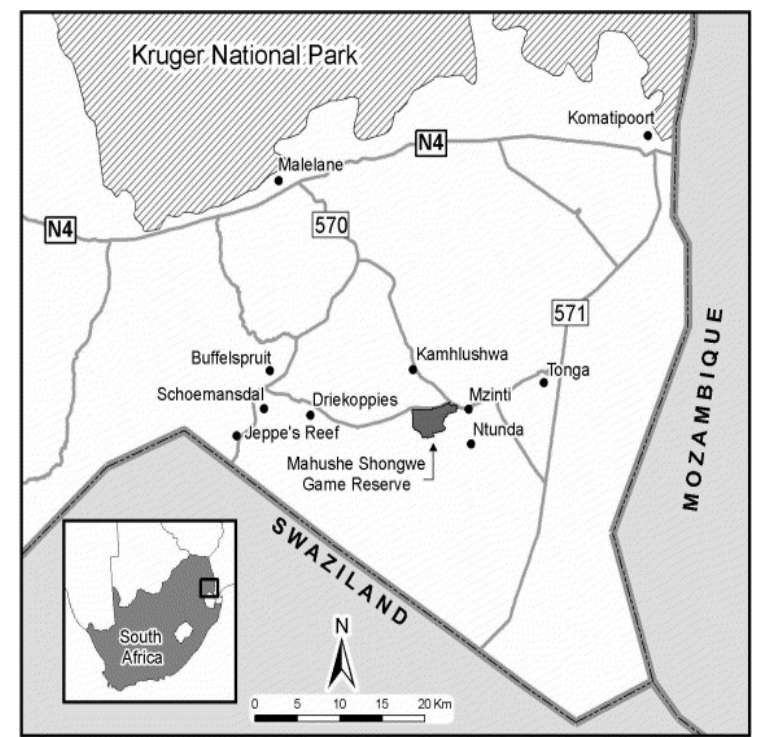

Figure 1: Location where study took place (Source: http://www.sciencedirect. org/maps). was therefore able to speak about whatever she deemed as relevant or poignant in her life. Once the narrative had been collected, it was transcribed and translated from SiSwati into English by a SiSwati firstlanguage research assistant. This was done by employing a hermeneutic approach [44].

Participant observations were conducted in order to provide a deeper understanding of the experience of being an immigrant and living with a disability. This was done by paying special attention to the way in which the participant negotiated physical obstacles in her environment, as well as the nature of her interactions with family members and members of the community. These were recorded using Spradley's guidelines for participant observation [45]. Researcher and research mediator reflections were documented in order to account for subjectivity and bias.

In order to understand the way in which the context of violence and poverty impacted on the participant's experiences as an immigrant with a disability, data were analysed by exploring the relationship between events and characters, and the temporal and spatial domains in which stories were told. This was done by identifying the following core aspects of narrative construction [37,38,40,42]:

- Positioning of the narrator, characters and events within the story

- Temporal and spatial domains within which events are constructed

- Development of a narrative plot

By interrogating these core aspects of narrative construction, attempts were made to identify the ways in which the participant made sense of her experiences [35,36], her attempts to organise the past, present and future into a meaningful pattern [40], and her ability to integrate a variety of roles and values into her narrative [41]. These aspects of narrative construction were analysed relative to the narrative identity that she created. In addition, thematic analysis [46] was applied in order to provide further insight into the intersectionality between immigration status, violence, disability and context on identity construction.

A number of measures were put in place to ensure trustworthiness of findings. Interviews were conducted in the participant's home language by a research mediator who was a local woman with a physical disability. This implied a degree of shared knowledge between the participant and the research mediator, and allowed for detailed descriptions of personal and often traumatic narratives to emerge. In addition, trustworthiness was ensured by visiting the participant on numerous occasions, and providing her with opportunities to verify our understanding of the way in which she made sense of her experiences. This was supplemented by a triangulation of data collection methods; the use of audit trails in the form of reflective journaling, and the use of verbatim quotes in documenting the findings.

\section{Results}

This case study revealed that the experience of immigration, violence, disability and poverty resulted in a multitude of traumas which significantly affected the construction of a resilient identity. Significantly, the context of violence and poverty were central to the ways in which the participant made sense of her experiences. Given her vulnerability as an immigrant woman with a disability, living in the context of poverty, the participant had received few opportunities to talk openly about her experiences or to report on the violence to which she had been exposed. However, once she was given the opportunity 
to talk about these, it emerged that she had difficulty in developing any form of narrative sequence or consequence, with each traumatic event fighting for dominance within her story. This had a significant impact on her attempts to develop a coherent sense of identity.

By focussing on the core aspects of narrative construction $[37,38,40,42]$ a number of salient features emerged which contribute towards the extant repository of knowledge on identity development amongst immigrant women. These are discussed below:

\section{The positioning of the narrator, characters and events within the story}

The participant did not locate her status as an immigrant as central to her narrative, but instead this was woven into the complexities associated with establishing roles as a daughter, wife, mother, and member of a community. When asked to tell her story, she began by documenting how her relationship failed as a result of her disability, by saying "I was married, then I got injured, then my husband left me. We separated because I was now disabled." She continued by describing how her disability was sustained, by saying "I became disabled in February 1984. My husband was from Mozambique, so I went with him to Mozambique. It was the war at that time. So they came to the house and they stabbed me."

The participant rapidly shifts the orientation of the narrative away from her attack to documenting her hospitalisation in Maputo, and the difficulties incurred when her parents wanted to take her back to South Africa, two years after the incident, for better medical care. She describes her husband's opposition to her going back to South Africa and how her parents took her across the border, regardless. She describes the difficulty of getting across the border after having lost everything, including her South African identity book and passport, by saying

"Oh - it was so difficult because I did not have any papers - no identity book, no passport, nothing. So at the border they were saying 'no, you are not South African. We cannot let you come.' But then my father spoke to them and explained my situation and they let me in. But then in South Africa they were saying I was an illegal from Mozambique so I couldn't get a wheelchair, crutches, nothing."

She continues to describe the conflict between her and her husband, and the challenges and expense involved in accessing medical help, given her status as an immigrant, her disability, and lack of assistive devices and social support. She emphasizes her mother's support during this time and discusses how, after the death of her mother, she was no longer able to attend her medical follow-up appointments because she had no one to assist her in getting to the hospital.

She returns to discussing her unhappiness in her relationship, the way in which the community responded to her disability, and the psychological violence that she endured, saying

"So then my husband also came to South Africa and he was working in Johannesburg at that time, and it caused problems in my life. On the days he was coming from Johannesburg, he was staying at my house and then tomorrow you hear news about me from the neighbours, like I am unable to work in the house but I can sleep with a man."

She continues to explain how she tried to get out of this relationship, but her husband refused, and began to abuse her sexually. She recounts this by saying

"I also became sick and no one was helping me. The neighbours were telling people not to help me because I was an illegal and because of my disability. I asked people from the church, and the pastors to help me, but they were all saying "no, there is nothing we can do." My mother was dead, and there was no one to help me. I was young and my husband and the people in my community were doing anything they liked to me. So I became a victim."

As the participant recounts her story of victimisation, she reflects on the poverty that she experienced after the war, and this brings her to what was arguably her most painful experience. She recalls:

"It was so painful, my heart was so painful. We had nothing. Everything was taken during the war. We didn't even have a chair. All the furniture was burnt by the soldiers. My son was also injured during the war because they burnt the house and we tried to run away from the fire. I was carrying my small baby. The soldiers took the baby from my back and threw him into the fire. He burnt until he died. My elder son was lucky because the soldiers felt sorry for him. They grabbed him with their hands and walked a short distance. You know what? We were many in that house. They put us inside with other people and burnt the house. So the soldiers, we knew them, they were our neighbours, and they were liking some people. The one with my son called me, and said 'run away with this child."'

In the extract above, it is significant to note how the central event of sustaining a disability is alluded to but not discussed, highlighting the participant's inability to transform the combination of emotional and physical pain into words. The participant describes a multitude of traumas here, and the staccato structure of her sentences and lack of chronological ordering highlights the embodiment of chaos [31]. The information presented here is dense and complex, involving violence, suspicion and mistrust, the responsibility of being a mother and the fear of imminent death as the house was set on fire, the notion of being 'lucky' and being pulled out of the house with the opportunity to escape, only to have one son injured, her baby murdered, and to sustain paraplegia as a result of being stabbed.

The narrative rapidly shifts to the participant's discussion of the challenges of rebuilding her life from nothing, once she returned to South Africa, and the process involved in obtaining her papers to prove herself as a legal citizen. These are woven into the psychological violence inflicted on her by the community when she fell pregnant:

"You know it was difficult for me because people were thinking I was an illegal from Mozambique so it was difficult for me to get the care that I needed. And then people were saying 'how can it be that I am pregnant?' They were asking me, how do I have sex with a man, being disabled? So the father of the baby was disappearing, because of all the talk from the neighbours. My days to deliver were coming, and I had no money to get to the hospital. But oh! It was embarrassing for me to be pregnant. I was afraid of myself, the way I was, and the nurses were saying 'who did this to you?!' Like as a disabled person you are not supposed to sleep with a man, like you are an animal. The other women at the clinic were pointing fingers at me, talking a lot, saying 'If I were you, I would not do that' or 'Stop this and don't do it again! Look at you!' like I have done something wrong, like I am not supposed to have feelings for a man."

The extracts above highlight the participant's difficulty in aligning herself with characters in the narrative. The community's response to her as an immigrant together with the stigma associated with disability serve to isolate her, and in this way her physical and psychosocial access to emotional support is severely restricted. This highlights her vulnerability as both an immigrant and a woman with a disability. 
The extracts also reveal that although the participant takes control of the narrative, as characterised by the extended accounts she provides and her consistent use of the personal pronoun 'I' [38], she also portrays a variety of identities and continually shifts between a number of different positions, including being an immigrant, a disabled woman, a victim, a mother, a wife and a daughter. Consequently, as she changes her role in relation to the different events described, her position changes relative to the other characters. She highlights her dependence on others, given her disability, while at the same time revealing the lack of social support offered by the community. This implies that at times the participant aligns herself with the characters in the narrative, while at other times she positions herself in contrast to them. In so doing, she reflects an inability to create a coherent sense of self, and as a result, the listener questions who the participant 'really' is.

\section{Temporal and spatial domains within which events are constructed}

The narrative is told in the past tense, and while the participant oscillates between different events in the past, there is an absence of reflection on the present, and no anticipation of the future, resulting in a sense of unpredictability and chaos. Clear spatial boundaries are created within the narrative by referring to the countries she has inhabited and her experiences in these countries, the effects of her husband working as a migrant labourer in Johannesburg, the clinics and hospitals where she was treated, and the physical location where the injury was sustained. However, temporal boundaries are poorly demarcated, resulting in a lack of narrative cohesion. Although the participant clearly positions her story in relation to the war in Mozambique, and her injury sustained in February 1984, all other events are described in the past tense but without reference to temporal boundaries, and with no sequential or chronological ordering. As a result, there is no evidence that the participant views the events as sequentially related or of consequence to each other. This implies a difficulty in differentiating between the traumas of being an immigrant woman, a person with a disability, and the effects of violence and poverty on her life, creating a sense of being trapped in the unbearable past.

\section{Development of a narrative plot}

The content of the narrative is dominated by human rights violations which are documented without sequence or consequence and as a result are unable to be incorporated into a story which society will view as 'acceptable'. Thus the narrative remains a list of fragmented and chaotic episodic events with no evidence of a central plot. In this way, the participant is only able to hint towards the horror of her experiences. This sense of chaos negates the space for reflection, and compounds the experience of not only producing a chaotic narrative, but also living a chaotic life [31]. As a result, the participant has difficulty in creating a coherent sense of self, as she is continually forced to shift positions in order to deal with the competing traumas in her life. Significantly there is no resolution or conclusion to the story, but instead the participant returns repeatedly to describing the traumatic events which dominate her narrative, once again highlighting her inability to derive any form of narrative sequence or consequence from her experiences.

\section{Discussion}

Narrative inquiry provided a unique method to explore the complex interaction between disability and violence as experienced by a female immigrant living in a rural area, with each of these aspects fighting for dominance within the narrative. The complex combination of horror and trauma which the participant experienced appear to threaten her sense of self, and as a consequence, the narrative is defined by the challenges that she faces in establishing a coherent sense of self. The impact of these traumas, together with limited opportunities to talk about them results in a fragmented and chaotic life story, devoid of sequence and consequence. It is, however, this chaos which appears to be fundamental to our understanding of the life experiences of female immigrants.

Conceptualising identity construction from a narrative perspective allowed the individual to position herself in multiple roles in relation to the boundaries of time and space that were created within the narrative. Figure 2 below reflects a visual representation of the way in which narrative identity is constructed in relation to time and space. This demonstrates the ways in which temporal and spatial boundaries appear to constrain the individual's ability to make sense of past experiences, and consequently affect the development of a coherent sense of self.

As evidenced in Figure 2, the notion of time is intersected by the notion of space, with identity construction occurring somewhere in the middle, depending on the individual's ability to make sense of life circumstances. In the case of an immigrant woman, the opportunities which she has to make sense of her life experiences and consequently to develop a cohesive and resilient sense of identity are confined by the physical, emotional and geographical spaces in which she exists. In the case of the participant described in this paper, her life experiences are constrained geographically by her status as an immigrant [while in Mozambique, and being perceived as an illegal immigrant upon returning to South Africa], physically in terms of her disability, and emotionally in terms of the various manifestations of violence and exploitation to which she has been exposed. This implies that identity construction is dependent on the way in which life experiences are made sense of and incorporated into the spatial and temporal ordering of narrative processes. In situations where an individual has sufficient support and access to resources, both positive and negative life experiences may be incorporated into the life story and the individual is able to reflect on these sequentially, observing the consequences of

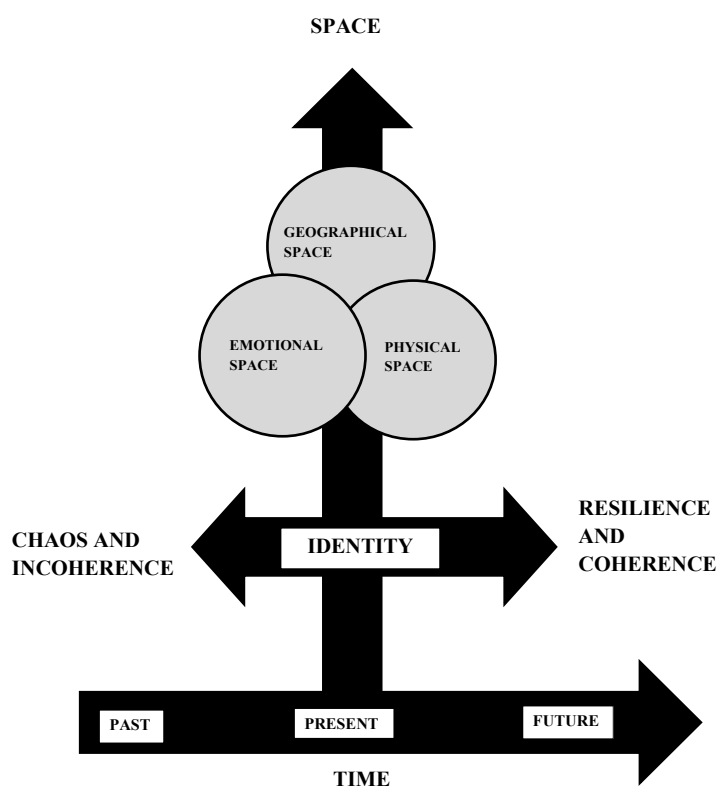

Figure 2: The impact of living as an immigrant with a disability in the context of poverty and violence: Identity construction within the realm of time and space. 
actions, and in so doing to learn from experiences, ultimately resulting in a coherent and resilient sense of self. However, in situations where the individual is vulnerable, as in the case of an immigrant woman with a disability, the repeated exposure to violence and exploitation, coupled with limited access to resources and poor social support prevent her from successfully making sense of life experiences. This results in the inability to derive any form of sequence or consequence to life experiences and ultimately the life story and one's sense of self becomes chaotic and incoherent. The lack of ability to make sense of life experiences, together with limited access to social support and an absence of social networks results in the individual remaining trapped in the unbearable past, which further challenges resilience. This serves to strengthen the negative cycle of hopelessness, oppression, and isolation, resulting in the inability to break free from the experience of chaos, perpetuating the cycle of weakened resilience, and increasing the individual's risk for being exposed to violence and exploitation.

\section{Conclusion}

By means of a single case study, this paper suggests ways in which the context of poverty and violence impact on the lives of female immigrants with disabilities, challenging the formation of a coherent and resilient sense of identity. This highlights how, despite comprehensive and well-designed policies, guidelines and legislation intended to protect the rights of all citizens, including immigrants and people with disabilities, many of these people continue to be exposed to multiple forms of violence and exploitation, resulting in social isolation and a decreased sense of resilience.

The findings of this study suggest narrative inquiry as a potentially appropriate tool for exploring the lived experiences of female immigrants. In particular, the findings advocate the importance of listening to unconventional narratives which do not conform to traditional narrative formats, since they provide insight into the reality of lived experience that cannot be achieved using other methods of data collection. It is therefore incumbent on us as researchers to be aware of our innate desire to hear stories of resilience [31], and to acknowledge that alternative realities exist. Part of the difficulty in acknowledging that alternative realities exist is the knowledge that by conducting narrow investigations or framing our studies by asking guiding questions, we as researchers are complicit in denying the reality of lived experience among vulnerable members of society.

Although the nature of narratives defined by multiple traumas may be chaotic, making them difficult to listen to and difficult to relate to, their value seems to be in the individual's ability to identify, isolate and narrate episodic events. This creates an opportunity for slowing the narrative down in order to allow for reflection and interpretation of events, experiences and emotions, and serves as a precursor to developing a testimony [31]. By allowing female immigrants to tell their stories, they are able to take on the responsibility of becoming witnesses to the atrocities that they have experienced. As these are shared with the listener, the narrative is transformed into moral responsibility. In so doing, testimony to a reality which was previously denied is concretised, creating a sense of moral responsibility to which society needs to respond.

\section{Acknowledgements}

Research grants to conduct this research were obtained through the Carnegie Corporation of New York and the University of the Witwatersrand Health Communication Project via South African Netherlands research Programme on Alternatives in Development [SANPAD] funding.

The authors would also like to acknowledge Mrs LindiweThobela and Ms
Zelda Mubi who assisted with data collection and translation and transcription of the interview.

\section{References}

1. Raj A, Silverman J (2002) Violence against immigrant women: the roles of culture, context and legal immigrant status on intimate partner violence. Violence Against Women 8: 367-398.

2. Fernbrant C, Essen B, Ostergren P, Cantor Graae E (2011) Perceived threat of violence and exposure to physical violence against foreign-born women: A Swedish population-based study. Women's Health Issues 21: 206-213.

3. Jasperse $M$, Ward C, Jose $P$ (2012) Identity, perceived religious discrimination and psychological well-being in Muslim immigrant women. Applied Psychology 61: $250-271$

4. Amanor-Boadu Y, Messing J, Stith S, Anderson J, O'Sullivan C, et al. (2012) Immigrant and non-immigrant women: Factors that predict leaving an abusive relationship. Violence Against Women 18: 611-633.

5. Crenshaw K (1991) Mapping the margins: Intersectionality, identity politics, and violence against women of color. Stanford Law Review 43: 1241-1299.

6. MacLachlan M, Swartz L (2009) Disability and International Development Towards Inclusive Global Health. Springer: New York.

7. Van Rooy G, Amadhila EM, Mufune P, Swartz L, Mannan M, et al. (2012) Perceived barriers to accessing health services among people with disabilities in rural northern Namibia. Disability \& Society 27: 761-775.

8. http://www.who.int/disabilities/world_report/2011/en/index.html

9. Garcia-Moreno C, Jansen HA, Ellsberg M, Heise L, Watts C (2006) Prevalence of intimate partner violence: Findings from the WHO multi-country study on women's health and domestic violence. The Lancet 368: 1260-1269.

10. Abramsky T, Watts CH, Moreno CG, Devries K, Kiss L, et al. (2011) What factors are associated with recent intimate partner violence? Findings from the WHO multi-country study on women's health and domestic violence. BMC Public Health 11: 1-17.

11. Ward C, Artz L, Berg J, Boonzaaier F, Crawford-Browne S, et al. (2012). Violence, violence prevention, and safety: A research agenda for South Africa S Afr Med J 102: 215-218.

12. Plummer SB, Findley PA (2012) Women with disabilities' experience with physical and sexual abuse: A review of the literature and implications for the field. Trauma, Violence and Abuse 13: 15-29.

13. Caldwell J, Caldwell P, Orubuloye I (1992) The family and sexual networking in Sub-Saharan Africa: Historical regional differences and present-day implications. Population Studies 46: 385-410.

14. Scheper-Hughes N, Bourgois $P$ (2004) Introduction: Making Sense of Violence. In N. Scheper-Hughes \& P. Bourgois (Eds). Violence in War and Peace. Blackwell Publishing, Oxford, United Kingdom

15. Matzopoulos R, Bowman B, Butchart A, Mercy J (2008) Background on violence and its prevention in low- and middle- income countries. International Journal of Injury Control and Safety Promotion 15: 177-187.

16. Tregenna $F(2012)$ What are the distributional implications of halving poverty in South Africa when growth alone is not enough? Applied Economics 44: 25772596.

17. Watermeyer J, Barratt J (2013) "I live in a bubble": Speech-language therapy and audiology students' expectations and experiences of a rural community work practicum. Rural Remote Health 13: 2131.

18. Engelbrecht $L$ (2012) Border strategy difficult in absence of national security policy.

19. Polzer T (2010) Population Movements in and to South Africa: Migration Fact Sheet 1. University of the Witwatersrand Forced Migration Studies Programme.

20. Maloy B (2012) The impact of legal and illegal migration on the Defence Security of South Africa: Distribution Statement.

21. Hughes K, Bellis MA, Jones L, Wood S, Batres G, et al. (2012) Prevalence and risk of violence against adults with disabilities: A systematic review and metaanalysis of observational studies. The Lancet 379: 1621-1629.

22. World Health Organisation (2002) Sexual and Reproductive Health.

23. Cerulo K (1997) Identity Construction: New Issues, New Directions. Annual Review of Sociology 23: 385-409. 
Citation: Neille J, Penn C (2014) "My heart was so painful": A Narrative Inquiry into the Impact of Immigration Status, Violence, Disability and Poverty on Identity Construction. Arts Social Sci J S1: 007. doi: 10.4172/2151-6200.S1-007

Page 7 of 7

24. Schafer R (1992) Retelling a life: Narrations and Dialogue in Psychoanalysis. Rochester, New York.

25. Cameron JE (2004) A three-factor model of social identity. Self and Identity 3 : 239-262.

26. Davis K (2008) Intersectinality as a buzzword: A sociology of science perspective on what makes a feminist theory successful. Feminist Theory 9: 67-85.

27. Somers MR (1994) The narrative constitution of identity: A relational and network approach. Theory and Society 23: 605-649.

28. Odero M, Hatcher A, Bryant C, Onono M, Romito P, et al. (2014) Responses to and resources for intimate partner violence: qualitative findings from women, men and service providers in rural Kenya. Journal of Interpersonal Violence 29: 783-805.

29. Conroy A (2014) Gender, power and intimate partner violence: A study on couples from rural Malawi. Journal of Interpersonal Violence 29: 866-888.

30. Kirshner J (2012) "We are Gauteng people": Chanllenging the politics of Xenophobia in Khutsong, South Africa. Antipode 44: 1307-1328.

31. Frank AW (1995) The wounded storyteller: Body, Illness and Ethics. University of Chicago Press, Chicago.

32. Bessareb D, Ng'andu (2010) Yarning about yarning as a legitimate method in indigenous research. International Journal of Critical Indigenous Studies 3 : 37-50.

33. Banks-Wallace J (1998) Emancipatory potential of storytelling in a group. Image J Nurs Sch 30: 17-21.

34. McAdams D (2001) The psychology of life stories. Review of General Psychology 5: 100-122.

35. Shakespeare T (1996) Disability, Identity and Difference. In C. Barnes and G.
Mercer (Eds). Exploring the Divide (pp. 94-113). Leeds: The Disability Press.

36. Holstein, J.A. \&Gubrium, J.F. (2012). Varieties of Narrative Analysis. Sage Publications, Los Angeles.

37. Clandinin J, Rosiek J (2007) Mapping a Landscape of Narrative Inquiry: Borderland Spaces and Tensions, pp. 35- 75 in Clandinin, J. (Ed.) Handbook of Narrative Inquiry: Mapping Methodology, Thousand Islands, London, New Dehli; Sage.

38. Bamberg M (2012) Narrative practice and identity navigation. In JA Holstein, JF Gubrium (Eds). Varieties of Narrative Analysis. Sage, Los Angeles.

39. McAdams D (1993) The Stories We Live By: Personal Myths and the Making of the Self. Guilford Press, New York.

40. Clandinin DJ, Connelly FM (2000) Narrative Inquiry: Experience and Story in Qualitative Research. Jossey Bass, San Francisco.

41. Riessman CK (2008) Narrative Methods for the Human Sciences. Sage Publications, London.

42. Mattingly C (1994) The concept of therapeutic 'emplotment'. Soc Sci Med 38 811-822.

43. Neille J (2013) Context, culture and disability: A narrative inquiry into the lived experience of adults with disabilities living in a rural area. Unpublished $\mathrm{PhD}$ Thesis of the University of the Witwatersrand: Johannesburg, South Africa.

44. Drennan G, Levett A, Swartz L (1991) Hidden dimensions of power and resistance in the translation process: A South African Study. Cult Med Psychiatry 15: 361-381.

45. Spradley J (1980) Participant Observation. Fort Worth: Harcourt Brace Jovanovich College Publishers.

46. Braun V, Clarke V (2006) Using thematic analysis in psychology. Qualitative Research in Psychology 3: 77-101.

This article was originally published in a special issue, Violence Against Immigrant Women: A Global Perspective Throughout the Life-Cycle handled by Editors. Nawal H. Ammar, University of Ontario Institute of Technology (UOIT), Canada; Arshia U. Zaidi, University of Ontario Institute of Technology (UOIT), Canada 